\title{
Electro and magnetorheological fluid damper study with controllable field- flow analysis for parallel plate duct
}

\author{
Rajender Kumar', Anil Kumar², Vijender Gill ${ }^{3 *}$, Jitender Sheoran ${ }^{3}$, Sarita ${ }^{4}$, Sunil Nain ${ }^{5}$ and \\ Promila $^{6}$ \\ Department of Basic Engineering, CCSHAU, Hisar, Haryana ${ }^{1}$ \\ Manager, Engineering Services, KEC International Ltd, Gurgaon ${ }^{2}$ \\ Department of Mechanical Engineering, Govt. Polytechnic, Hisar $^{3}$ \\ Department of Biomedical Engineering, DCRUST, Murthal, Sonipat ${ }^{4}$ \\ Department of Mechanical Engineering, GJUS\&T, Hisar ${ }^{5}$ \\ MC, HSAMB, Hisar ${ }^{6}$
}

Received: 09-July-2020; Revised: 20-August-2020; Accepted: 25-August-2020

(C)2020 Rajender Kumar et al. This is an open access article distributed under the Creative Commons Attribution (CC BY) License, which permits unrestricted use, distribution, and reproduction in any medium, provided the original work is properly cited.

\begin{abstract}
Electro and magneto-rheological shock absorbers made most attractive choice of semi-active vibration control systems. A mg fluid damper is a system in the magnetic fluid where a damper is filled with a magnetic fluid. A magneto-rheological fluid damper is a system where a damper is filled with a magnetic fluid. Within this system the external current (voltage) regulating the magnetic field varies as an electromagnet in the magnetic fields of the piston within the damper. By adjusting the magnetic strength of the piston, the damping force of the damper is controlled. This paper offers a conceptual mathematical method for analyzing the behaviour, by combining fluid-mechanic approach to the fundamental equation of Herschel-Bulkley, of the field controllable electro-and magneto-rheological fluid flow through the parallel plate duct. Electro and magneto-rheological shock absorbers are built with simple expressions for the pressure drop solution. The quasi-stable flow study from Herschel-Bulkley would then be extended to include accumulator pressure, shear thickening and shear thinning effects. This, thus, accounts for the nonlinear dynamic electro and magnetorheological fluid damper behaviour. Non-dimensional plug thickness is calculated for the creation of simpler descriptions for the exact model. This article offers a theoretical model of magneto-rheological dampers that regulate the area to predict the established behaviour. This has been shown to be an electro and magneto-rheological fluid threshold modeling device, with the simplified H-Bulkley model for parallel plates. The results of the assessments show that the most promising magneto-rheological damper with less than 3 percent of the relative maximum errors are modern semiactive instruments for structural seismic response observed.
\end{abstract}

\section{Keywords}

Parallel plate duct, Rheological fluid, etc.

\section{Introduction}

Electro and magneto- rheological fluids (MRF) constitute the materials that respond to a field and change its rheological performance [1]. This change is usually characterized with the creation of a yield stress, which enhances monotonously in field applied. The electro and magneto-rheological fluids are mostly non-colloidal suspensions of polarizing particle suspensions in size of a few microns [2, 3].

*Author for correspondence
Magneto-rheological fluid first discovered in 1948 and patented in 1951 at the US National Standards Bureau was developed by Jacob Rabinow [4-6]. This work was almost concurrently done by Winslow also. Winslow's first description of the effect was to use fine powder oil dispersions. Electro-rheological behaviour thus, also called the Winslow effect [7-9].

Magneto-rheological particles are magnetized to create a linear chain; with the changing magnetic field, the resulting drop intensity can be achieved, which results in changing fluidity. The MRF characteristics return to the Newtonian fluid if the magnetic field is removed. If the magnetic field is not 
applied by the MRF, the magnetic particles and a carrier liquid have a certain damping force [10].

The rheological response of electro and magnetic properties-rheological fluids results from the polarization caused by an external field of the particles suspended. The outer field causes dipoles in the dielectric particles, which are then aggregated [11]. They begin to create fibrous structures between the electrodes that align with the direction of the field being applied. They do so in order to reduce the interaction between dipole and dipole energy, since the minimization of potential energy meets stability [12]. Such a chain-similar to structures restricts the fluid movement and increase the suspension viscosity. It thus changes the rheology of the electro and magneto-rheological fluid to nearly a solid state [13]. The mechanical energy required to break such structures in the chains increases with the increase in the field leading to a yield stress depends on the surface. Electro and magneto-rheological fluids act like Newtonian fluids in the absence of an applied field. A Bingham model in which MR fluid is defined only by a particular threshold or yield stress as a Newtonian fluid is the simplest and most commonly known. Subsequently, Herschel-Bulkley fluid model was used that considered the post fluence pseudo plastic behaviour [14].

These materials' rheological behaviour can before and after execution be divided into two separate regimes [15]. Before the yield point, the force increases in a nearly linear fashion with an increase in the velocity [16]. It is known as action before yielding. When the absorber force reaches the yield point, transfer occurs from well before yield to the post - yield area due to stiction phenomena, which results in overshoot type behaviour in the system [17]. For most instruments, for example, clutches, dampers, the post-production action of magneto rheological fluids is the main method of action [18, 19].

This paper represents a theoretical model of area controllable magneto-rheological dampers for predicting the behaviour that has been developed. The Herschel-Bulkley method is constructed to define ideal expressions for rheological fluid flow among parallel plates in fluid flow. For determining the pressure drop, according to the material characteristics, morphology, and volume rate of these fluids, a basic expression is given. It is observed that simplified model may be taken as an outstanding estimation to the precise result. It is demonstrated that rheological fluid dampers exert the large force to damp the vibrations with a slight increase of current for the same damper configuration.

\section{Mathematical modeling of electro and magneto-rheological fluid dampers}

\subsection{Viscous fluid flow analysis:}

Consider the laminar flow between two different parallel sheets or plates, located at a distance, $H$, apart (Figure 1). Considering a small rectangular fluid element of length, $\delta z$, thickness, $\delta h$ and unit width, $w$, as shown in Figure 2. The constitutive equation for non-Newtonian fluid is given as.

$\tau_{h z}=\mu\left(\frac{d u}{d h}\right)^{n}$

where $u$ is the fluid velocity. The laminar flow momentum equation has given as

$\tau_{h z}=-h \frac{d P}{d z}$

From Equation (1) and (2)

$$
\left(\frac{d u}{d h}\right)=-\left(-h \frac{d p / d z}{\mu}\right)^{\frac{1}{n}}
$$

The above equation shows that, $\frac{d u}{d r}<0$, i.e. velocity decreases with respect to $h$. Integrate Equation (3) with respect to $h$ and applying boundary condition, i.e. at $h=H^{\prime}, u=0$ which gives the velocity profile of the fluid

$u=\frac{n}{n+1} \frac{\mu}{d p / d z}\left\{\left(-h \frac{d p / d z}{\mu}\right)^{\frac{n+1}{n}}-\left(-H^{\prime} \frac{d p / d z}{\mu}\right)^{\frac{n+1}{n}}\right\}$

For the value of $n=1$, velocity profile becomes

$$
u=-\frac{1}{2 \mu} \frac{d p}{d z}\left(H^{\prime 2}-h^{2}\right)
$$

The velocity profile curve of the fluid is shown by the equation (5). It is parabolic in nature and the maximum velocity occurs at the centre. The Volumetric flow rate is given by [20]

$Q=2 \int_{0}^{H^{\prime}} u w d h$ 


$$
\begin{aligned}
& Q=2 w \int_{0}^{H^{\prime}} \frac{n}{n+1} \frac{\mu}{d P / d z}\left[\left(-\frac{h}{\mu} \frac{d P}{d z}\right)^{\frac{n+1}{n}}-\left(-\frac{H^{\prime}}{\mu} \frac{d P}{d z}\right)^{\frac{n+1}{n}}\right] d h \\
& Q=2 w \frac{n}{2 n+1}\left(\frac{H^{\prime}}{\mu}\right)^{\frac{1}{n}}\left(\frac{d P}{d z}\right)^{\frac{1}{n}} H^{\prime 2}
\end{aligned}
$$

The Pressure gradient is, thus, given as

$$
\frac{d P}{d z}=\left(\frac{2 n+1}{n} \frac{2 Q}{w H^{2}}\right) \frac{2 \mu}{H}
$$

when $n$ is substituted by 1 , the above equation reduces to

$$
\frac{d P}{d z}=\frac{12 \mu Q}{w H^{3}}
$$

Which is a pressure gradient equation between two parallel plates for Newtonian fluid flow.

\section{Electro and magneto-rheological fluid flow in a parallel duct}

3.1Mathematical modelling based on the herschelbulkley model

The gap between piston and cylinder housing is generally termed as flow gap. Due to the slight flow difference and the diameter of the damper piston the axisymmetric flow can be approximated by the flow through a parallel frame. Suppose parallel plates are fixed and the fluid flow between the plates is supplied through a steady pressure gradient, $P^{\prime}$.

The Herschel-Bulkley constitutive equation [9] for parallel plates is given as

$$
\begin{cases}\tau_{h z}=\tau_{y}+k\left(\frac{d u}{d h}\right)^{n} & \left|\tau_{h z}\right| \geq \tau_{y} \\ \frac{d u}{d h}=0 & \left|\tau_{h z}\right| \leq \tau_{y}\end{cases}
$$

Where $\tau_{h z}$ is shear Stress, $\frac{d u}{d h}$ is shear strain, $\tau_{y}$ is fluid yield stress and $K, n$ are fluid index parameters [21].

Let us consider laminar flow between two parallel plates located at a distance $H$ apart as shown in Figure 1. The flow rate is constant in the area of the plug flow and defined as a region lacking yield ( $\left.0 \leq h \leq h_{p}\right)$ where $h_{p}$ is plug thickness. At the boundary of non-yield region, i.e. at $h=h_{p}$, $\tau_{h z}=\tau_{y}$. Thus, plug thickness is given as

$$
h_{p}=-\frac{\tau_{y}}{d P / d z}
$$

Substituting Equation (9) in Equation (2) gives;

$$
\frac{d u}{d h}=-\left(-\frac{d P / d z}{k} h-\frac{\tau_{y}}{k}\right)^{\frac{1}{n}}
$$

Negative sign indicates $\frac{d u}{d h}<0$ i.e. velocity decreases in yield flow region. Integrating Equation (11) with respect to $h$ and applying boundary condition, i.e. at $h=H^{\prime}, u=0$ gives the yield flow velocity profile $\left(h_{p} \leq h \leq H^{\prime}\right)$ region as [22]

$u=\left(\frac{n}{n+1}\right) \frac{k}{d P / d z}\left[\left\{\left[\begin{array}{l}\left.\left\{-h \frac{d P / d z}{k}-\frac{\tau_{y}}{k}\right)^{n+1 / n}\right\} \\ \left.-\left\{-H^{\prime} \frac{d P / d z}{k}-\frac{\tau_{y}}{k}\right)^{n+1 / n}\right]\end{array}\right]\right.\right.$

Similarly, non-yield flow field velocity profile ( $\left.0 \leq h \leq h_{p}\right)$ is derived as

$u_{p}=\left(\frac{n}{n+1}\right) \frac{k}{d P / d z}\left[\begin{array}{l}\left\{\left(-h_{p} \frac{d P / d z}{k}-\frac{\tau_{y}}{k}\right)^{n+1 / n}\right\} \\ -\left\{\left(-H^{\prime} \frac{d P / d z}{k}-\frac{\tau_{y}}{k}\right)^{n+1 / n}\right\}\end{array}\right]$

The volumetric flow rate is given by combining effect of yield and non-yield flow region:

$Q=2 \int_{h_{p}}^{H^{\prime}} u w d h+2 u_{p} w h_{p}$

$$
\begin{aligned}
& Q=\left(P^{\prime} H^{\prime}-\tau_{y}\right)^{\frac{n+1}{n}} \frac{n}{2 n+1} \frac{1}{k^{\frac{i}{n}}} \frac{2 w H^{\prime 2}}{P^{\prime} H^{\prime}} \\
& {\left[\frac{n\left(\tau_{y} / P^{\prime} H^{\prime}\right)+(n+1)}{n+1}\right]}
\end{aligned}
$$


Rajender Kumar et al.

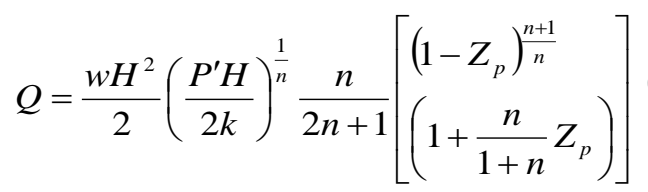

where $Z_{p}=\frac{\tau_{y}}{P^{\prime} H^{\prime}} \quad$ and $\quad H^{\prime}=\frac{H}{2}$

Defining $V$ as dimensionless variable as

$V=\left(\frac{2 n+1}{2 n}\right)^{n}\left(\frac{4 Q}{w H^{2}}\right)^{n} \frac{2 k}{P^{\prime} H}$

It is possible to write equation (17) as

$V=\left[\left(1-Z_{p}\right)^{n+1}\left(1+\frac{n}{1+n} Z_{p}\right)^{n}\right]$

Expansion of Equation (18) yields;

$V=1+C_{1} Z_{p}+C_{2} Z_{p}{ }^{2}+C_{3} Z_{p}{ }^{3}$

where

$C_{1}=-\frac{2 n+1}{n+1} ; C_{2}=\frac{n(1+2 n)(1-n)}{2(n+1)^{2}} ; C_{3}=\frac{n\left(n^{2}+1\right)}{2(n+1)}$

For $Z_{p} \leq 0.5$, Suppose we have a linear relationship of $\mathrm{V}$ and $Z_{p}$ as $V=1+B Z_{p}$. For all values of $n$ linear approximation of Equation (19), gives

$V=1+\left(C_{1}+\frac{3}{8} C_{2}+\frac{3}{20} C_{3}\right) Z_{p}$ for $Z_{p} \leq 0.5$

Substituting values of $V, Z_{p}, C_{1}, C_{2}$ and $C_{3}$ in Eq. (20) provide us an expression for pressure gradient of a non-Newtonian fluid, in terms of yield stress as [23]:

$\frac{d P}{d z}=B \frac{2 \tau_{y}}{H}+\left(\frac{2 n+1}{n} \frac{2 Q}{w H^{2}}\right)^{n} \frac{2 k}{H}$

for $\frac{h_{p}}{h} \leq 0.5$

where

$B=\frac{2 n+1}{n+1}-\frac{3 n(1+2 n)(1-n)}{16(n+1)^{2}}-\frac{3 n\left(n^{2}+1\right)}{40(n+1)}$

The yield stress can play an important part in the loss of pressure assessment when the plug radius exceeds, $Z_{p}>0.5$, half the pipe radius. A nonlinear relationship between $V$ and $Z_{p}$ is known to provide a simplified expression for Equation (19) as

$V=B^{\prime} Z_{p}\left(1-Z_{p}\right)^{\beta} \quad$ for $\quad Z_{p}>0.5$

where $\beta$ and $B^{\prime}$ are power index function, $n$, as given in Table 2 and thus, pressure loss is determined from Equation (22) as

130

$$
\frac{d P}{d z}=\frac{2 \tau_{y}}{H\left[1-B_{0}\left(\frac{2 n+1}{n} \frac{2 Q}{w H^{2}}\right)^{\frac{n}{\beta}}\left(\frac{k}{\tau_{y}}\right)^{\frac{1}{\beta}}\right]} \text { for } \frac{h_{p}}{h}>0 .
$$

where $B_{0}=\left(B^{\prime}\right)^{-\frac{1}{\beta}}$ For a Newtonian fluid, $\tau_{y}=0$ and $n=1$. The parallel plate model Equation (21) is reduced to $\frac{d P}{d z}=\frac{12 \mu Q}{w H^{3}}$. The yield stress, $\tau_{y}$, is depends on the input current/magnetic field strength applied. The relation of yield stress to input current is given by

$\tau_{y}=2.7 \times 10^{4} I^{1.5}$

where the $\tau_{y}$ and $I$ are denoted in $\mathrm{Pa}$ and ampere respectively. The relation between the yield stress, $\tau_{y}$, and the magnetic field is given as

$\tau_{y}=\alpha B^{1.5}$

Where $\alpha$ is the material constant $(70 \mathrm{kPa} / \mathrm{T})$ and $\mathrm{B}$ is the magnetic field strength in tesla (T). Using Equations (21) \& (23), the pressure drop along Z direction may be written as

$$
\begin{gathered}
\Delta P=B \frac{2 L \tau_{y}}{H}+\left(\frac{2 n+1}{n} \frac{2 Q}{w H^{2}}\right)^{n} \frac{2 k L}{H} \text { for } \frac{h_{p}}{h} \leq 0.5 \\
\Delta P=\frac{2 L \tau_{y}}{\left[1-B_{0}\left(\frac{2 n+1}{n} \frac{2 Q}{w H^{2}}\right)^{\frac{n}{\beta}}\left(\frac{k}{\tau_{y}}\right)^{\frac{1}{\beta}}\right]} \text { for } \frac{h_{p}}{h}>0.5
\end{gathered}
$$

Drop in pressure results in the force output and is given as

$$
F=\Delta P A+F_{f} \operatorname{sign}\left(V^{\prime}\right)
$$

where the damper seal friction force is denoted by $F_{f}$ and is assumed as $50 \mathrm{~N}$.

\subsection{Mathematical modeling based on the Bingham model}

The Bingham plastic model can easily get after reduction of Herschel-Bulkley model for $n=1$. Substituting the values of various parameters from Table 1 and $n=1$, pressure gradient is given as

$\frac{d P}{d z}=\frac{12 k Q}{w H^{3}}+2.85 \frac{\tau_{y}}{H}$ for $\frac{h_{p}}{h} \leq 0.5$ 


$$
\frac{d P}{d z}=\frac{2 \tau_{y}}{H\left[1-0.593\left(\frac{6 Q k}{w H^{2} \tau_{y}}\right)^{0.380}\right]} \text { for } \frac{h_{p}}{h}>0.5(30)
$$

\section{Results and discussion}

The Herschel-Bulkley and Bingham model provide a collation of the exact and simplified parallel-plate model solution. The exact Equation (18) and the simplified Equations (20) \& (22) have been plotted for various values of non-dimensional plug thickness, $Z_{p}$, with the dimensionless volumetric flow rate, $V$, for parallel plate model in the fluid flow mode for different fluid parameters. As shown, in resulting graphs, Figure $3(a) \&(b)$, the simplified model is shown to be a successful approach to the right solution with a cumulative relative error of less than 3 percent.

Using geometric properties of rheological fluids as given in Table 2, Figure 4 \& Figure 5 gives the graphical representation of the pressure drop and force relations with velocity for a parallel plate model of electro and magneto-rheological fluid damper for fluid parameter $n=0.4$ and $n=1$. Straight line shows the behaviour of viscous fluid flow without any current. It has a linear relationship between pressure drop and velocity for $n=1$. Remaining curves show the pre-yield and post yield behaviour with current variation from 0.25 to 2 ampere for $n=0.4$. A better estimate of the exact solution for simplified model is given by comparing the complex and simplified versions of the parallel model plate. For HerschelBulkley model of parallel plate, one may observe a considerable variation of pressure drop and force with applied current when $n \neq 1$. Hence, with the same damper configuration, damper having electro and magneto-rheological fluid exerts large force to damp the vibration with a slight increase of current. This may be supplied by battery of an automobile very easily.

For fluid parameter $n=0.4$ and $n=1$, a graph between shear stress and shear strain is plotted and it is shown in Figure 6. The plastic behaviour of Bingham with a steady plastic viscosity in the region of low magnetic field strength can be observed with magneto-rheologic fluids. It exhibits nevertheless pseudo-plastic behaviour with field-dependent yield stress at higher magnetic field strengths.

Table $1 B^{\prime}, \beta$ and $\beta$ for different values of $n$

\begin{tabular}{llll}
\hline$n$ & $\beta$ & $B^{\prime}$ & $B_{0}=\left(B^{\prime}\right)^{-\frac{1}{\beta}}$ \\
\hline 1 & 2.629 & 3.952 & 0.593 \\
\hline 0.8 & 2.475 & 3.810 & 0.583 \\
\hline 0.4 & 1.816 & 2.727 & 0.575 \\
\hline
\end{tabular}

Table 2 The Materiel and physical properties of Herschel-Bulkley analysis

\begin{tabular}{ll}
\hline Parameter & Value (units) \\
\hline$k$ & $430 \mathrm{~Pa}-\mathrm{s}$ \\
\hline$n$ & 0.4 \\
\hline$\mu$ & $0.4 \mathrm{~Pa}-\mathrm{s}$ \\
\hline$H$ & $1 \times 10^{-3} \mathrm{~m}$ \\
\hline$L$ & $14 \times 10^{-3} \mathrm{~m}$ \\
\hline$w$ & $10 \times 10^{-3} \mathrm{~m}$ \\
\hline
\end{tabular}


Rajender Kumar et al.

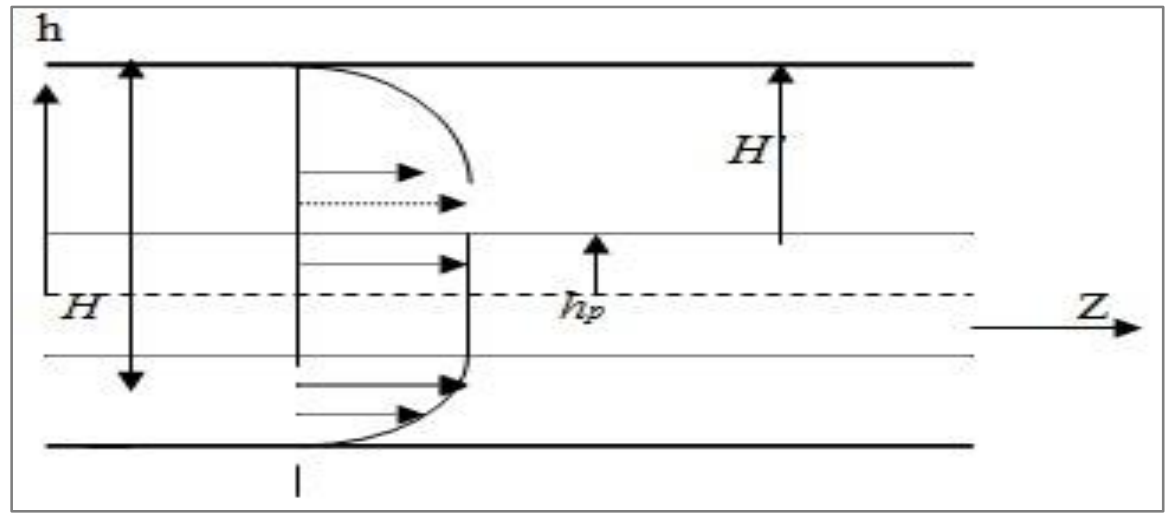

Figure 1 Non-Newtonian fluid flow description by parallel plate

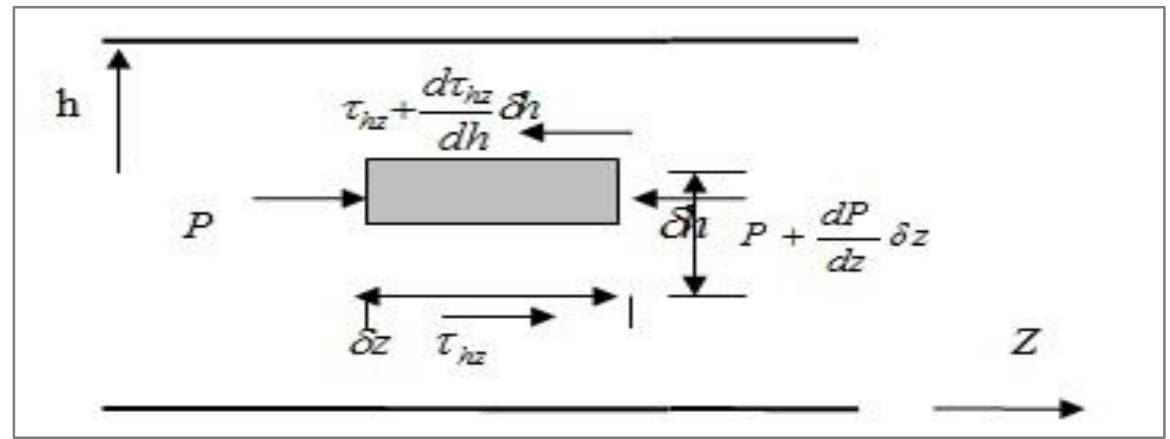

Figure 2 Free body diagram of laminar flow through parallel plate

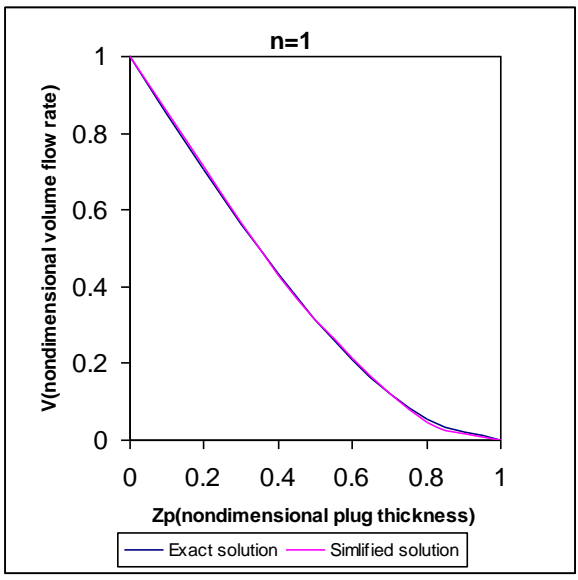

(a)

Figure 3 (a, b) A distinction between Herschel-Bulkley parallel plate flow accurately and simplified formulations for $n=1$ and $n=0.4$

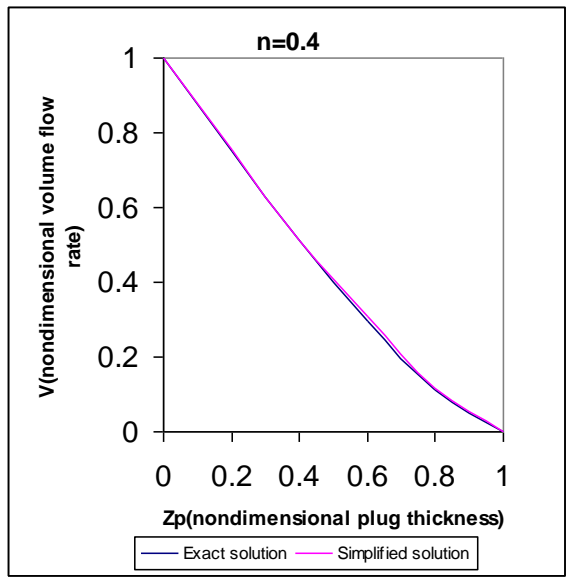

(b) 


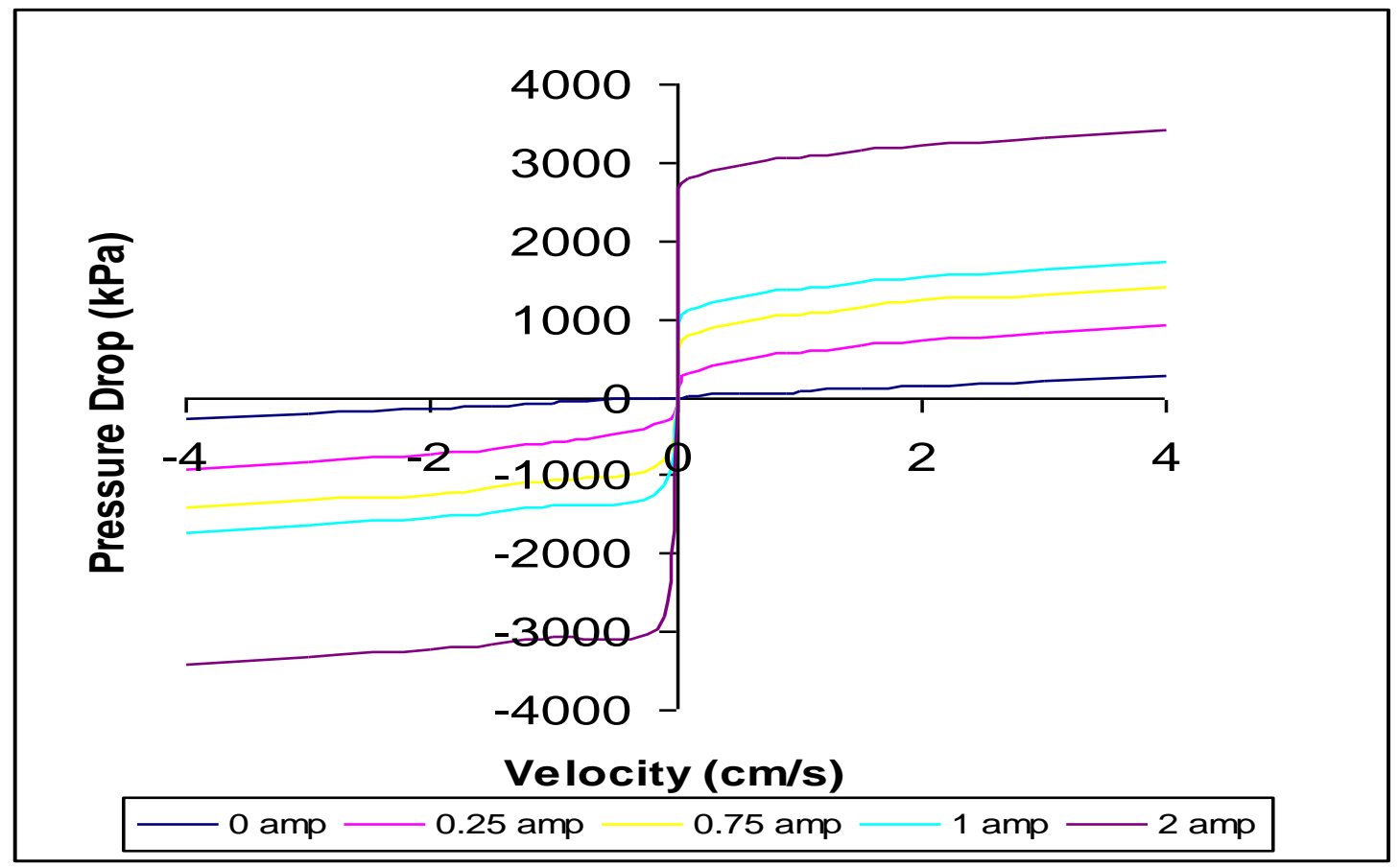

Figure 4 Pressure drop versus velocity relationship for parallel plate model

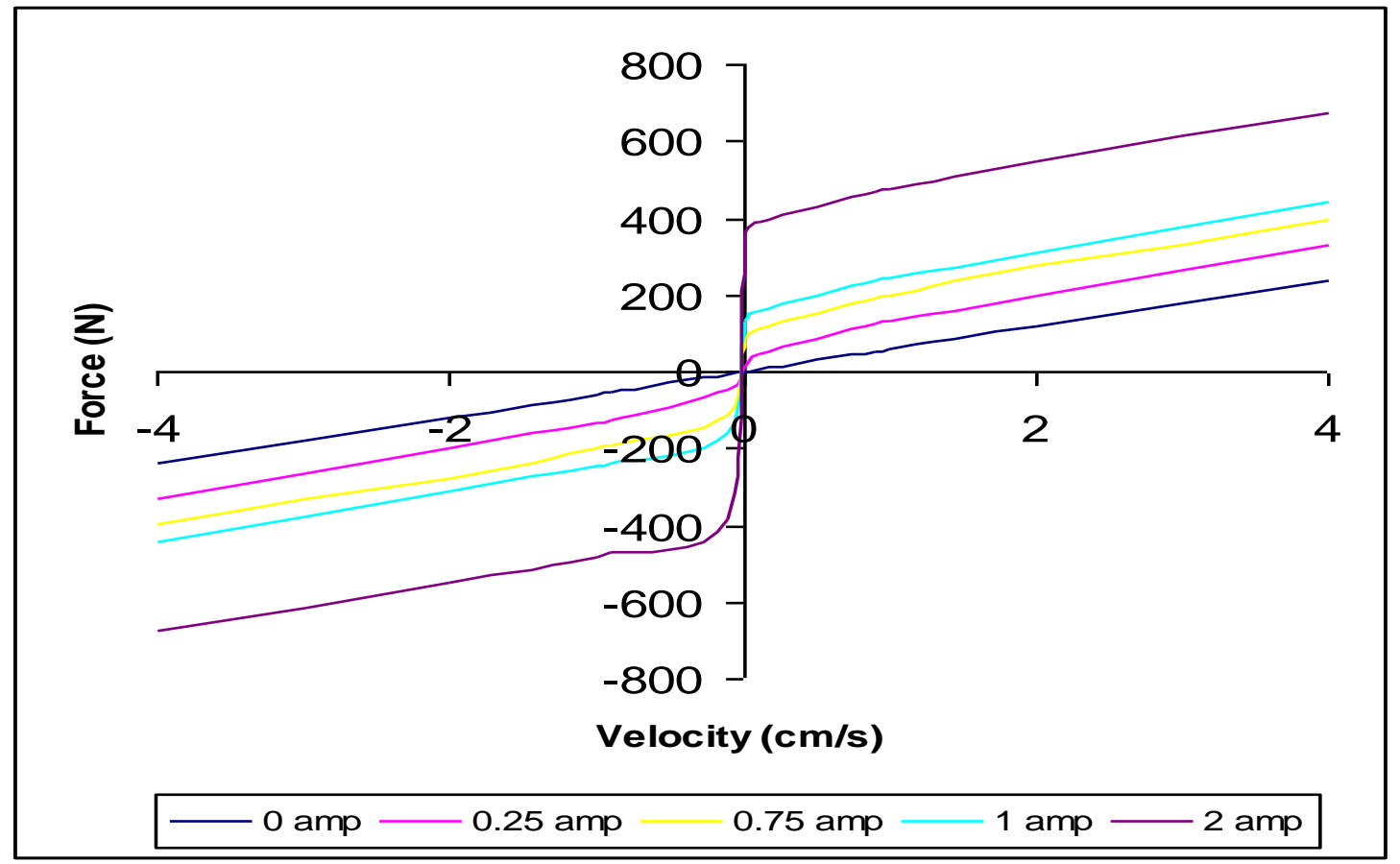

Figure 5 Force versus velocity for parallel plate model 


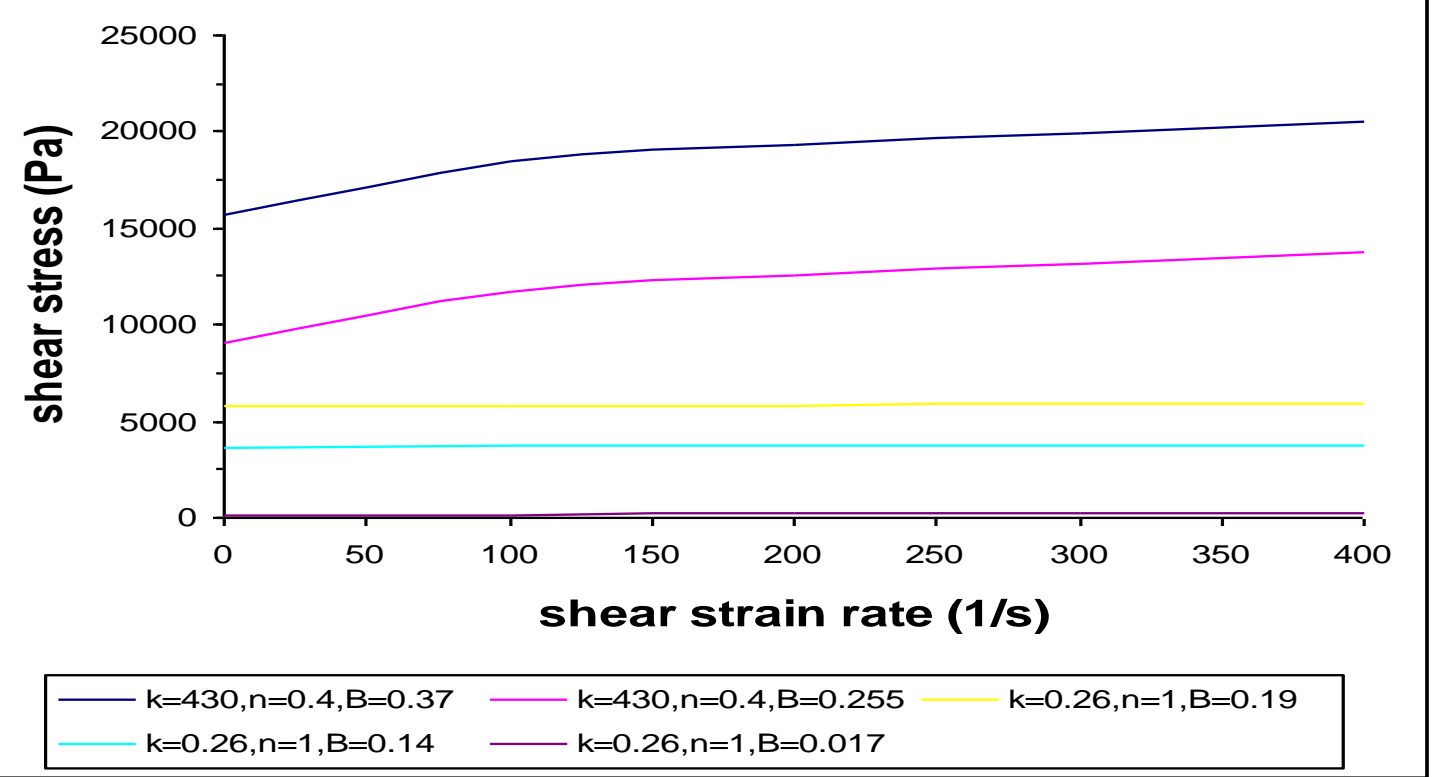

Figure 6 Shear stress and shear strain at different strengths of the magnetic field

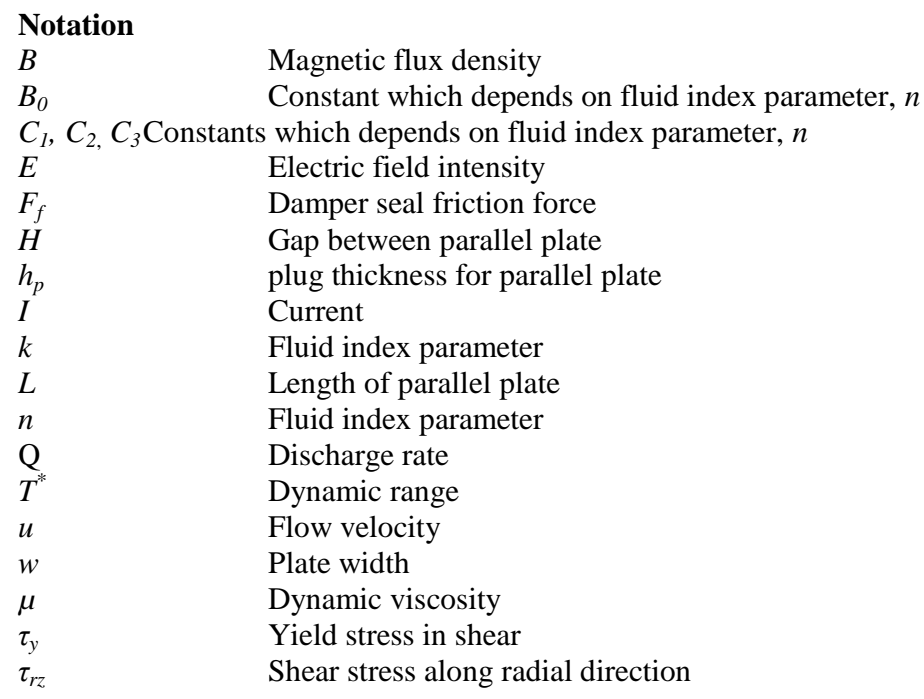

\section{Conclusion}

The pressure drop (gradient) must be defined with a simplified closed-form expression in terms of the material characteristics, morphology and volume flow rates. Comparing the detailed and simplified versions of the parallel plate model provides a better estimation to an accurate solution for simplified model. It is observed that less than $3 \%$ of the relative maximum error is found. For magneto-rheological fluids that can observe Bingham's plastic behaviour for steady plastic viscosity in the area of low magnetic field strength. Analytical results show that the modern semi active tools for structural seismic

response, reduction or broadband excitation control are the most promising magneto-rheological damper.

\section{Acknowledgment}

None.

\section{Conflicts of interest}

The authors have no conflicts of interest to declare.

\section{References}

[1] Kumar JS, Paul PS, Raghunathan G, Alex DG. A review of challenges and solutions in the preparation and use of magnetorheological fluids. International Journal of Mechanical and Materials Engineering. 2019; 14(13):1-18. 
[2] De Vicente J, Klingenberg DJ, Hidalgo-Alvarez R. Magnetorheological fluids: a review. Soft Matter. 2011; 7(8):3701-10.

[3] Sudo S, Funaoka M, Nishiyama H. Impact of droplets of magneto-rheological suspension under applied magnetic fields. Journal of Intelligent Material Systems and Structures. 2002; 13(7-8):409-13.

[4] Rabinow J. The Magnetic Fluid Clutch AIEE Transactions, 67.

[5] Wang X, Gordaninejad F. Herschel-bulkley analysis of electro-and magneto-rheological controllable fluids in flow mode. In electro-rheological fluids and magneto-rheological suspensions 2000 (pp. 568-78).

[6] Zhou H, Zhao W, Zhang H, Wang Y, Wu X, Sun Z. Magnetorheological seal: a review. International Journal of Applied Electromagnetics and Mechanics. 2020:1-24.

[7] Mäkelä KK. Characterization and performance of electrorheological fluids based on pine oils. Journal of Intelligent Material Systems and Structures. 1999; 10(8):609-14.

[8] Pfeiffer C, Mavroidis C, Bar-Cohen Y, Dolgin BP. Electrorheological-fluid-based force feedback device. In telemanipulator and telepresence technologies VI 1999 (pp. 88-99). International Society for Optics and Photonics.

[9] Adali S. Optimization of laminated composites and overview of smart material applications. In modern trends in composite laminates mechanics 2003 (pp. 227-80). Springer, Vienna.

[10] Chen DC, Chen LR. Application of the Taguchi method for finite element analysis of a shear-type magnetorheological fluid damper. Advances in Mechanical Engineering. 2020.

[11] Sheng P, Wen W. Electrorheological fluids: mechanisms, dynamics, and microfluidics applications. Annual Review of Fluid Mechanics. 2012; 44:143-74.

[12] Yu X, Cheng H, Zhang M, Zhao Y, Qu L, Shi G. Graphene-based smart materials. Nature Reviews Materials. 2017; 2(9):1-3.

[13] Rutten SH. Smart materials in automotive applications. Internship Report MT0319, Technische Universiteit Eindhoven, the Netherlands. 2003.

[14] Palomares E, Morales AL, Nieto AJ, Chicharro JM, Pintado P. Modelling magnetorheological dampers in preyield and postyield regions. Shock and Vibration. 2019.

[15] Wang X, Gordaninejad F. Field-controllable electroand magneto-rheological fluid dampers in flow mode using Herschel-Bulkley theory. In smart structures and materials 2000: damping and isolation 2000 (pp. 23243). International Society for Optics and Photonics.

[16] Frigaard IA, Paso KG, de Souza Mendes PR. Bingham's model in the oil and gas industry. Rheologica Acta. 2017; 56(3):259-82.

[17] Yang G, Spencer Jr BF, Jung HJ, Carlson JD. Phenomenological model of large-scale MR damper systems. In advances in building technology 2002 (pp. 545-52). Elsevier.
[18] Gavin H, Hoagg J, Dobossy M. Optimal design of MR dampers. In proceedings of us-japan workshop on smart structures for improved seismic performance in urban regions 2001 (pp. 225-36).

[19] Jalili N. A comparative study and analysis of semiactive vibration-control systems. J. Vib. Acoust. 2002; 124(4):593-605.

[20] Chambon G, Freydier P, Naaim M, Vila JP. Asymptotic expansion of the velocity field within the front of viscoplastic surges: comparison with experiments. Journal of Fluid Mechanics. 2020.

[21] Wang X, Gordaninejad F. Flow analysis of fieldcontrollable, electro-and magneto-rheological fluids using Herschel-Bulkley model. Journal of Intelligent Material Systems and Structures. 1999; 10(8):601-8.

[22] Wang X, Gordaninejad F. Flow analysis and modeling of field-controllable, electro-and magneto-rheological fluid dampers. Journal of Applied Mechanics. 2007; 74(1): 13-22.

[23] Choi SB, Song HJ, Lee HH, Lim SC, Kim JH, Choi HJ. Vibration control of a passenger vehicle featuring magnetorheological engine mounts. International Journal of Vehicle Design. 2003; 33(1-3):2-16.

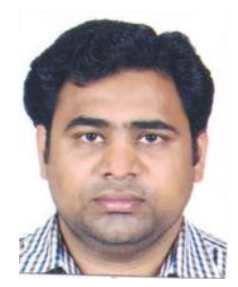

Rajender Kumar is currently an Assistant Professor in the faculty of Mechanical Engineering, Department of Basic Engineering at Chaudhary Charan Singh Haryana Agricultural University (CCSHAU), Hisar in India. Before his recent appointment at the CCSHAU, he was a lecturer in Mechanical Engineering under Directorate of Technical Education, Haryana and had Industrial experience of about one year as an Engineer. He is having a good blend of Teaching, Research, extension and industrial experience of more than 17 years. Rajender Kumar received his B.E. from CRSCE, Sonipat (Now Deenbandhu Chhotu Ram University of Science and Technology, Sonipat) and presently simultaneously pursuing $\mathrm{PhD}$ (Mechanical Engineering) from GJUS\&T, Hisar. He has good academic record with having an addition in specialization Operations Management from Symbiosis, Pune and Master in Business Administration from PTU, Jalandhar with his primary discipline i.e. Mechanical Engineering. He has delivered many online lectures through EduSat to all polytechnic colleges across Haryana. Er. Rajender Kumar published many papers in preferred, peer reviewed Journals and conferences and participated in a range of forums on agricultural machinery and implements. He also presented various academic as well as research-based papers at several national and international conferences including the International Society of Ergonomics, Melbourne; IIT Guwahati; NIT Kurukshetra and many SAUs and others in India and abroad. His research activities are currently twofold: while the first research activity is set to explore the developmental role in agriculture machinery and implements, ergonomically based equipment; the second major research theme that he is pursuing is focused on Biomaterials with In-Vivo/ In-Vitro study and Magneto- 
rheological fluids (MRF) with flow analysis. He has an active life member of Indian Society of Ergonomics, Institution of Engineers (India), Indian Society of Agricultural Engineers \& others.

Email: rksingh1279@yahoo.com

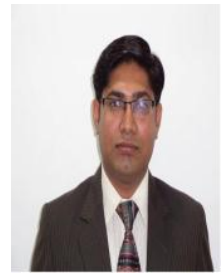

Anil Kumar is currently a Manager in KEC International Ltd. Gurgaon (Haryana) in India. He is having a good blend of 15 years Industrial experience. $\mathrm{He}$ received his B.Tech. from Regional Engineering College, Kurukshetra, Kurukshetra University (Now NIT, Kurukshetra) and M. Tech. from Punjab Engineering College, Chandigarh (Now PEC University of Technology, Chandigarh). He is having a wide exposure to balance of plant packages in Hydro Power, Thermal Power and Industrial units while working in KEC International Ltd, TOSHIBA Plant System and Services Corporation India Pvt. Ltd., GMR Enery and Indo-Canadian Consultancy Services Ltd. His area of interest is HVAC, Fire Fighting, Cooling Water System, Magneto-rheological fluids with flow analysis and Crane design along with various packages of plant design. He is having overseas experience in Japan (Tsurumi \&UmiShibaura) for many project work. At present, he is working as Mechanical Team Lead for various projects in SAARC region and Indian Region.

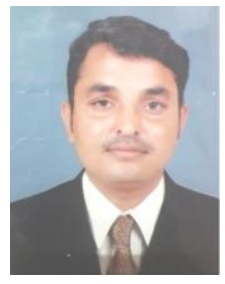

Vijender Singh Gill is currently a Lecturer in Mechanical Engineering in Govt Polytechnic, Hisar under Directorate of Technical Education Haryana. He is having a good experience of teaching and research of around 11 years. He has received his B. Tech., M. Tech. and Phd from Guru Jambheshwer University of Science and Technology, Hisar, Haryana (India). His area of interest is Adanace Manufacturing Processes, EDM, WEDM, Biomaterial and Mathematical Modelling. He has published articles in reputed, peer reviewed National and International Journals and Conferences.

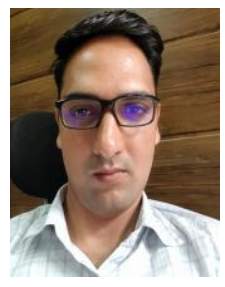

Jitender sheoran is currently working as lecturer in the Department of Mechanical Engineering, Government polytechnic Hisar under Directorate of Technical Education Haryana with an experience of teaching and research of more than 10 years. He has received $B$. E from Maharshi Dayanand university, Rohtak and M.Tech from Guru jambheshwar university of science and technology, Haryana in the field of Mechanical Engineering. He has participated in many online FDP and workshop programmes in research field under AICTE, MHRD, Govt of India. His Area of interest is Advanced manufacturing process and mathematical modeling. He has published articles in reputed peer reviewed National and International Journals and Conferences.

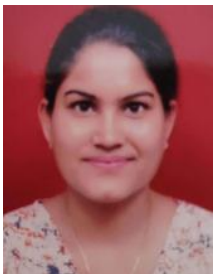

Sarita is currently working as Assistant professor in Department of Biomedical Engineering at Deenbandhu Chhotu Ram University of Science and Technology, Murthal, Haryana. She is having a good expertise in teaching and research more than 07 years. She has received his B. Tech. from MDU Rohtak, M. Tech. From MNNIT, Allahabad and pursuing Phd from MNNIT Allahabad. Her area of interest is Biomaterial and Biomechanics and Modelling simulation. She has awarded best poster presentation in Conference. She has published articles in reputed, peer reviewed National and International Journals and Conferences.

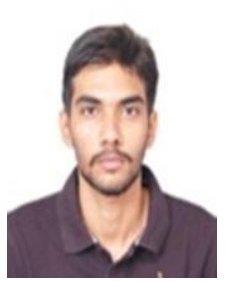

Sunil Kumar Nain is currently pursuing as a Research Scholar in the Department of Mechanical Engineering at Guru Jambheshwar University of Science and Technology in Hisar, Haryana. He has more than 3 years' industrial experience in the field of Quality Assurance. He is well qualified with undergraduate degree in B.Tech from Kurukshetra University (KUK) in Kurukshetra and M.Tech degree from GJUS\&T in Hisar, Haryana (India). He has many publications in various research journals including a number of National and International Conferences; International Conference on Optimization of Unconventional Machining in NIT, Kurukshetra (India) and National Conference on Medical Instruments and Biomaterials in DCRUST, Sonipat - Haryana (India). He has an active member of The Institution of Engineers (IEI) India. His area of interest for research is In-Vivo and InVitro study of Biodegradable Biomaterials and flow analysis.

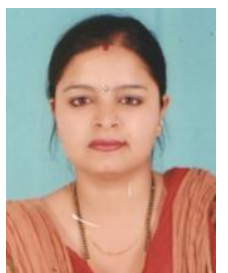

Promila is currently working as an Accountant in MC, Haryana State Agricultural Marketing Board, Hisar. Prior to her recent appointment, she was a lecturer in Commerce in Jaat College, Hisar under Kurukshetra University, Haryana and had also industrial experience. She has proved good expertise in teaching, research and Industrial of more than 11 years. The author has post graduated M.Sc and M.Com. She has specialized in MBA (Finance and International Business) from Guru Jambheshwar University of Science and Technology, Hisar. She was pursuing PhD from Kurukshetra University, Kurukshetra. She has many publications and is presently workings on many more papers. She has well experienced in the analysis and mathematical modeling. Her other areas of specialization include Management, Accountancy, International Finance in addition to Business Law. 